\title{
Maternal identification of hybrid eggs in Hexagrammos spp. by means of multiplex amplified product length polymorphism of mitochondrial DNA
}

\author{
Motoko R. Kimura $^{1, *}$, Takashi Yanagimoto ${ }^{2}$, Hiroyuki Munehara ${ }^{3}$ \\ ${ }^{1}$ Division of Biosphere Science, Graduate School of Environmental Science, and ${ }^{3}$ Usujiri Fisheries Station, \\ Field Science Center for Northern Biosphere, Hokkaido University, 152 Usujiri, Hakodate, Hokkaido 041-1613, Japan \\ ${ }^{2}$ Oceanic Squid Section, National Research Institute of Far Seas Fisheries, Fisheries Research Agency, 2-12-4, Fukuura, \\ Kanazawa, Yokohama, Kanagawa 236-8648, Japan
}

\begin{abstract}
Hybridization has been frequently observed among 3 species of greenlings (genus Hexagrammos) common in waters off Japan. In order to estimate the frequency of hybridization events from egg masses collected from male territories, efficient maternal identification of numerous egg masses is required. A novel streamlined approach for maternal identification of 3 Hexagrammos spp. was developed using multiplex amplified product length polymorphism (APLP) analysis of the mitochondrial cytochrome $b$ (Cytb) and the 12S and 16S ribosomal RNA (12-16S rRNA) regions. Concurrent use of species-specific primer sets permits the amplification of different-sized PCR products, diagnosing each species through one procedure of PCR in a single reaction tube. The APLP method produced more rapid, reliable, and cost-efficient species identifications compared to those from an established restriction fragment length polymorphism (RFLP) protocol.
\end{abstract}

KEY WORDS: APLP · Maternal identification · Hybridization · Mitochondrial DNA · Multiplex PCR · Hexagrammos spp. $\cdot$ Cytochrome $b \cdot 12 \mathrm{~S}$ and $16 \mathrm{~S}$ ribosomal RNA

\section{INTRODUCTION}

Hybrid zones have been recognized in various groups of fishes (Arnold 1997) and their study provides an opportunity to understand evolutionary processes of reproductive isolation and speciation (Jiggins \& Mallet 2000). Most studies of hybrid zones are restricted to freshwater species (e.g. Scribner et al. 2000) and there is little current information regarding marine fishes (Nielsen et al. 2004). Generally, hybrid zones are relatively broader in the sea than on land, a result consistent with higher realized dispersal of marine populations (van Herwerden \& Doherty 2006). Genetic screening will require substantially more specimens for analysis; thus low-cost and efficient methods of hybrid identification are necessary prerequisites for advancing the study of hybrid zones in marine fishes.
Species in the genus Hexagrammos are endemic to the North Pacific Ocean and widely distributed along coastal areas (Rutenberg 1970). H. otakii, H. agrammus and $H$. octogrammus were recently reported to hybridize with one another in the southern Hokkaido and Tohoku districts of Japan (Balanov \& Antonenko 1999, Brykov \& Podlesnykh 2001). Males of these congeneric species establish breeding territories and care for egg masses deposited by multiple females until hatching (Crow et al. 1997). Although such a breeding system readily permits paternal identification by collection of eggs from the male breeding territories, maternal identification by direct observation is difficult because females leave the territories soon after spawning.

Genetic variation of mitochondrial DNA (mtDNA) is a powerful tool for determining female parentage in teleost fishes, due to rapid nucleotide sequence evolu- 
tion and asexual maternal inheritance in most vertebrates (Avise \& Lansman 1983, Nei 1987). The nonrecombining mtDNA genome experiences an effective rate of genetic drift 4 -fold greater than that for nuclear DNA because of haploid maternal transmission, leading to faster accumulation of fixed differences among closely related species (Nei 1987). A polymerase chain reaction and restriction fragment length polymorphism (PCR-RFLP) method developed for the region spanning the mitochondrial $12 \mathrm{~S}$ and 16S ribosomal RNA genes (Yanagimoto 2003) permits unequivocal maternal identification of these Hexagrammos species. Although the PCR-RFLP method is highly effective, it involves 2 procedures: amplification of a target region by PCR, and subsequent digestion by restriction enzymes. More efficient methods are necessary for the high sample throughput required to study hybrid zones in marine species.

In this study, we report the development of a multiplex amplified product length polymorphism (APLP) protocol for determining species maternity in 3 Hexagrammos species. This method is based upon PCR amplification of diagnostic fragments using speciesspecific primers. Concurrent use of these primer sets generates different-sized PCR amplicons, diagnosing each species simultaneously. Since this method requires only one PCR reaction within a single reaction tube per sample, it is likely to substantially reduce both cost and time for hybrid identification. This method has recently been applied in studies of humans (Umetsu et al. 2005), identification of fungal pathogens (Dendis et al. 2003) and ecological field studies supporting conservation management that required screening thousands of samples (Pank et al. 2001, Hosseini et al. 2007). Here we confirm the reliability and efficiency of the APLP method in direct comparison with an existing PCR-RFLP protocol.

\section{MATERIALS AND METHODS}

Specimen collection. Adult specimens of 3 Hexagrammos spp. were captured by gill nets and traps at a coastal reef off Usujiri, Japan, where interspecific Hexagrammos hybrids have been reported, and at Mie and Akkeshi, Japan, where hybrids have not been reported (Fig. 1; Yabe et al. 1991). Fishes were identified by external morphology based upon the number of lateral lines, frap pairs, and caudal fin shape, following Shinohara (1994) and Nakabo (2000). Individuals possessing intermediate characters were excluded from DNA analysis as putative hybrids. Egg masses were collected from the male territories of 3 Hexagrammos spp. at the coast of Usujiri using SCUBA (Fig. 1). Each egg mass was kept separate until hatching, and one larva was randomly

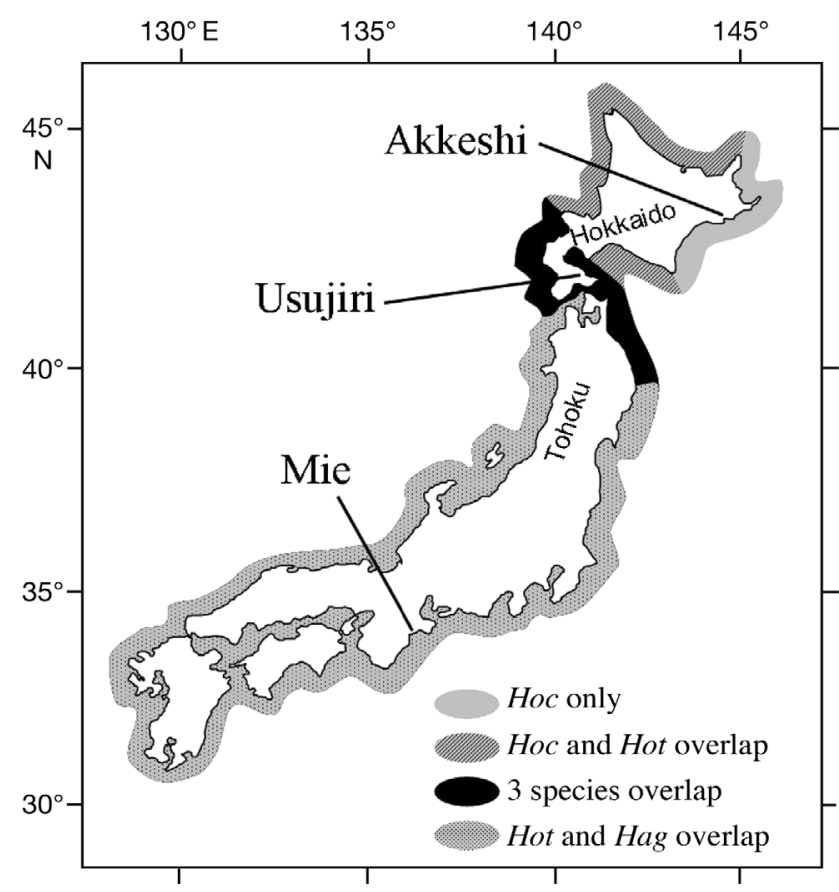

Fig. 1. Hexagrammos spp. Geographic distributions of 3 Hexagrammos species (Hot: H. otakii, Hag: H. agrammus, Hoc: $H$. octogrammus; overlap of 2 or more species also indicated) and locations where specimens were sampled. Adult specimens were sampled from Usujiri, Mie and Akkeshi. All egg masses were sampled from Usujiri

selected from each for genetic analysis. All tissues from adults and larvae were preserved in $99 \%$ ethanol in a freezer at $-30^{\circ} \mathrm{C}$. The number of specimens of adults and larvae are shown in Table 1.

DNA extraction, PCR reaction and sequencing. Total genomic DNA was extracted using the Puregene DNA purification kit (Gentra Systems) according to manufacturer's instructions and stored in a refrigerator at $4^{\circ} \mathrm{C}$ until use. The primer sets, Cyt $b$-F, $5^{\prime}$-ATGGC-

Table 1. Hexagrammos spp. Numbers of specimens of adults and larvae used for analysis

\begin{tabular}{|llr|}
\hline & Site & $\mathrm{N}$ \\
\hline Adults & & \\
H. otakii & Usujiri & 6 \\
H. agrammus & Mie & 6 \\
& Usujiri & 6 \\
H. octogrammus & Mie & 6 \\
Total & Usujiri & 6 \\
& Akkeshi & 6 \\
Larvae of territorial male & & 36 \\
H. otakii & & \\
H. agrammus & & 11 \\
H. octogrammus & & 11 \\
Total & & 10 \\
& & 32 \\
\hline
\end{tabular}


AAGCCTACGAAAAA-3' (forward primer); Cyt $b$-R, 5'-TCCTAAGGCCTTGTTTTCTA-3' (reverse primer); 12S-F, 5'-CGGGAACTACGAGCAAAAG-3' (forward primer); and 16S-R, 5'-TCTTTTAGTCTTTCCCTGGGG-3' (reverse primer), were designed from sequences of the cytochrome $b$ region (Cytb, AF087409, AF087410 and AF087412) and the 12S and 16S rRNA regions (12-16S rRNA, AB084628, AB084629 and AB084631) reported by Yanagimoto (2003) and Yanagimoto \& Kobayashi (2004). PCR amplification was carried out with an ABI 9700 thermal cycler (Applied Biosystems) using the following thermal cycle profile: denaturation at $94^{\circ} \mathrm{C}$ for $2 \mathrm{~min}, 40$ cycles of denaturation at $94^{\circ} \mathrm{C}$ for $30 \mathrm{~s}$, annealing at $55^{\circ} \mathrm{C}$ for $30 \mathrm{~s}$ and extension at $72^{\circ} \mathrm{C}$ for $2 \mathrm{~min}$, followed by extension at $72^{\circ} \mathrm{C}$ for 7 min. PCR reactions were conducted with $1 \mu \mathrm{l}$ of template DNA (20 to $40 \mathrm{ng} \mathrm{\mu l}^{-1}$ ), $24 \mu \mathrm{l}$ of PCR buffer $(\mathrm{pH}$ 8.0) containing of $0.5 \mu \mathrm{l}$ of each primer $(50 \mu \mathrm{M}), 2.5 \mu \mathrm{l}$ of dNTP mix (2.5 mM each), $2.5 \mu \mathrm{l}$ of $10 \times$ Ex Taq buffer (TaKaRa Bio), $0.13 \mu \mathrm{l}$ of TaKaRa Ex Taq HS DNA polymerase $\left(5 \mathrm{U} \mathrm{\mu l}^{-1}\right.$; TaKaRa Bio) and $17.87 \mu \mathrm{l}$ of sterile distilled water.

After purification with a GFX filter (Amersham Biosciences), PCR products were used as templates for direct cycle sequencing reactions using the same primers as described above and the ABI Big Dye Terminator cycle sequencing kit v3.1 (Applied Biosystems) following manufacturer's instructions. Automated DNA sequencing of both strands was conducted with an ABI PRISM 3130 XL DNA sequencer (Applied Biosystems).

Individual sequences were aligned with DNA Space v3.5 (Hitachi Software Engineering), and Arlequin v3.1 (Excoffier et al. 2005) was used for detection and enumeration of haplotypes. Haplotype sequences have been deposited in DDBJ GeneBank with the following accession numbers (Cyt b, AB290730-AB2907969; 1216S rRNA, AB290770-AB290802). Phylogenetic analysis among haplotypes was carried out using MEGA 3.1 software (Kumar et al. 2004). Nucleotide divergences were computed using the Kimura 2-parameter model (Kimura 1980) and a phylogenetic tree was constructed using the neighbor-joining method (Saitou \& Nei 1987). Robustness of topology nodes was tested using the bootstrap method with 1000 replications (Felsenstein 1985).

Design of species-specific primers and multiplex APLP analysis. Three speciesspecific forward primers were designed from the haplotype sequences of the Cytb and 12-16S regions such that at least 1
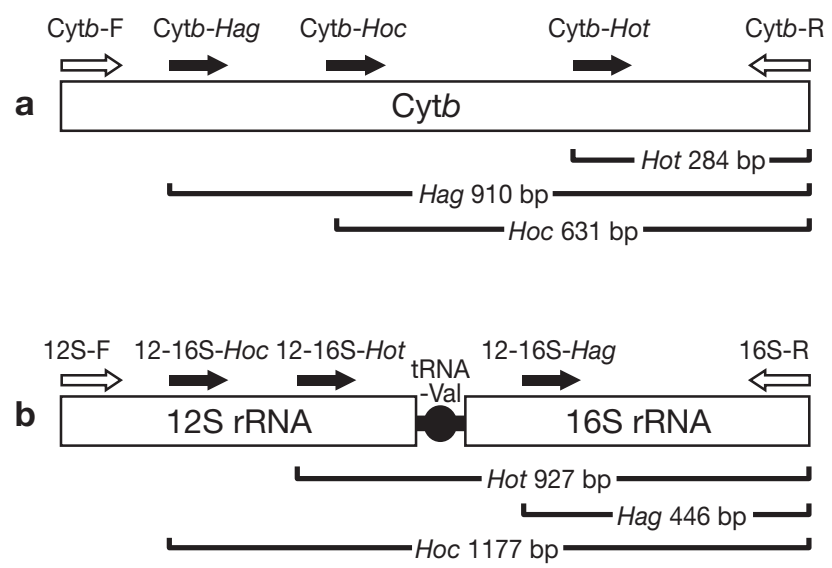

Fig. 2. Hexagrammos spp. Schematic representation of (a) Cytb and (b) 12-16S rRNA regions, indicating relative annealing sites and orientation of the primers used for DNA sequencing (open arrows) and species specific primers (solid arrows). Right- and left-pointing arrows: forward and reverse primers, respectively. The expected fragment sizes for each species are indicated below. Species abbreviations are given in Table 2

nucleotide at the 3 '-end of the primer was unique to 1 target species in the alignment (Fig 2). Primers designed for both the Cyt $b$ and 12-16S rRNA regions (Table 2) were positioned internal to the forward and reverse primer used for sequencing so as to generate unambiguously diagnostic-sized fragments for each

Table 2. Hexagrammos spp. Multiplex primer sets, melting temperatures $\left(\mathrm{T}_{\mathrm{m}}\right)$ and product size for cytochrome $b(\mathrm{Cyt} b)$ and the 12-16S rRNA amplified product length polymorphism. Sequences of 3 species-specific primers (forward primers) and the single reverse primer are shown. Hot, Hag and Hoc refer to $H$. otakii, $H$. agrammus, and $H$. octogrammus, respectively. Sequences of the non-target species are shown below the sequence of each species-specific primer (orthologue). Nucleotide differences between each species-specific primer and its ortholog are indicated in boldface type

\begin{tabular}{|c|c|c|c|c|}
\hline Locus & Primer & Sequence $\left(5^{\prime}-3^{\prime}\right)$ & $\begin{array}{c}\mathrm{T}_{\mathrm{m}} \\
\left({ }^{\circ} \mathrm{C}\right)\end{array}$ & $\begin{array}{l}\text { Product } \\
\text { size }\end{array}$ \\
\hline \multirow[t]{4}{*}{ Cyt $b$} & $\begin{array}{l}\text { Cyt } b-H o t \\
\text { (ortholog) }\end{array}$ & $\begin{array}{l}\text { TCCCTAACAAGCTAGGGGGT } \\
\text { TCCCCAACAAACTAGGAGGC }\end{array}$ & 63.5 & $284 \mathrm{bp}$ \\
\hline & $\begin{array}{l}\text { Cytb-Hag } \\
\text { (ortholog) }\end{array}$ & $\begin{array}{l}\text { CGGCTGACTTATCCGTAATC } \\
\text { CGGCTGACTTATCCGTAATT }\end{array}$ & 61.0 & $910 \mathrm{bp}$ \\
\hline & $\begin{array}{l}\text { Cytb-Hoc } \\
\text { (ortholog) }\end{array}$ & $\begin{array}{l}\text { CTCAGTTGACAACGCCACAT } \\
\text { CTCAGTTGACAATGCCACAC }\end{array}$ & 63.8 & $631 \mathrm{bp}$ \\
\hline & $\begin{array}{l}\text { Cyt } b-\mathrm{R} \\
\text { (reverse) }\end{array}$ & TCCTAAGGCCTTGTTTTCTA & 58.0 & \\
\hline \multirow[t]{4}{*}{$\begin{array}{l}12-16 \mathrm{~S} \\
\text { rRNA }\end{array}$} & $\begin{array}{l}\text { 12-16S-Hot } \\
\text { (ortholog) }\end{array}$ & $\begin{array}{l}\text { ACACTGAGAAGTCACCCGTT } \\
\text { ACACTGAGAAGTCACCCGTG }\end{array}$ & 61.2 & $927 \mathrm{bp}$ \\
\hline & $\begin{array}{l}\text { 12-16S-Hag } \\
\text { (ortholog) }\end{array}$ & $\begin{array}{l}\text { AGCCTGACCCCTATTGATGT } \\
\text { AGTCTGACCCCTATTGATGC }\end{array}$ & 62.3 & $446 \mathrm{bp}$ \\
\hline & $\begin{array}{l}\text { 12-16S-Hoc } \\
\text { (ortholog) }\end{array}$ & $\begin{array}{l}\text { ACAGCGAATACGGAGGGTGT } \\
\text { ACAGCGAACACGGAAGGTGC }\end{array}$ & 65.6 & $1177 \mathrm{bp}$ \\
\hline & $\begin{array}{l}\text { 16S-R } \\
\text { (reverse) }\end{array}$ & TCTTTTAGTCTTTCССТGGGG & 63.1 & \\
\hline
\end{tabular}


species. For each amplicon, a single reverse primer (described in the previous section) was used concurrently with the 3 species-specific forward primers in a single tube for PCR amplification.

Each multiplex PCR was carried out with an ABI 9700 thermal cycler (Applied Biosystems) following the thermal cycle profile: denaturation at $94^{\circ} \mathrm{C}$ for $2 \mathrm{~min}$, 40 cycles of denaturation at $94^{\circ} \mathrm{C}$ for $30 \mathrm{~s}$, annealing at $60^{\circ} \mathrm{C}$ for $30 \mathrm{~s}$ and extension at $72^{\circ} \mathrm{C}$ for $2 \mathrm{~min}$, followed by extension at $72^{\circ} \mathrm{C}$ for $7 \mathrm{~min}$. Reactions were conducted by adding $1 \mu \mathrm{l}$ of template DNA (20 to $40 \mathrm{ng}$ $\mathrm{\mu l}^{-1}$ ) to $24 \mu \mathrm{l}$ of PCR mix buffer ( $\mathrm{pH}$ 8.0) containing of $0.5 \mu \mathrm{l}$ of each primer $(50 \mu \mathrm{M}), 2.5 \mu \mathrm{l}$ of dNTP mix (2.5 mM each), $2.5 \mu \mathrm{l}$ of PCR buffer, $0.13 \mu \mathrm{l}$ of Taq polymerase $\left(5 \mathrm{U} \mathrm{\mu l}^{-1}\right)$ and $16.87 \mu \mathrm{l}$ of sterile distilled water. Ampli Taq Gold (Applied Biosystems) DNA polymerase was used to assure high annealing stringency of species-specific primers to complementary diagnostic sites. When PCR amplification was inconsistent, possibly because of poor storage conditions and potentially degraded DNA, TaKaRa Ex Taq HS (TaKaRa Bio)

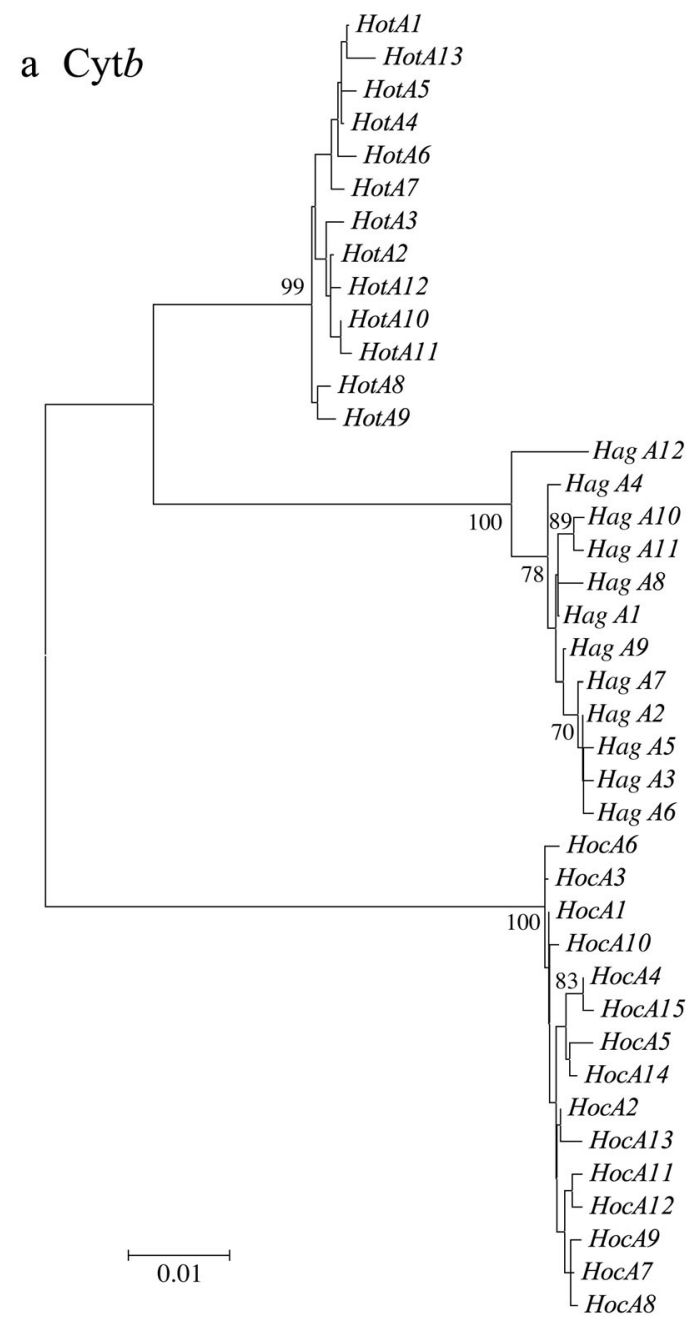

DNA polymerase was used instead of Ampli Taq Gold. PCR products were separated by electrophoresis on $1.5 \%$ agarose gels for $20 \mathrm{~min}$ at $100 \mathrm{~V}$, then visualized under UV light following staining with ethidium bromide.

PCR-RFLP analysis. To compare reliability and efficiency of the APLP method with an existing PCR-RFLP method, the same individuals were analyzed again using the latter method. The enzymes Dde I and Msp I were used to restrict the 12-16S rRNA gene fragment following Yanagimoto (2003). DNA Space v3.5 (Hitachi Software Engineering) was used to select the restriction enzymes Hinf I and Rsa I to screen variation in the Cytb gene fragment. Digestions were performed in $10 \mu \mathrm{l}$ volumes containing $8 \mu \mathrm{l}$ of PCR product, $4 \mathrm{U}$ of restriction enzyme, and $1 \mu \mathrm{l}$ of $10 \times$ buffer supplied by the manufacturer at $37^{\circ} \mathrm{C}$ for $5 \mathrm{~h}$ or longer. The reaction was stopped by heat inactivation by 15 min incubation at $65^{\circ} \mathrm{C}$. Restriction fragments were separated by electrophoresis on $2.0 \%$ agarose gels for $40 \mathrm{~min}$ at 100 $\mathrm{V}$ and visualized following ethidium bromide staining.

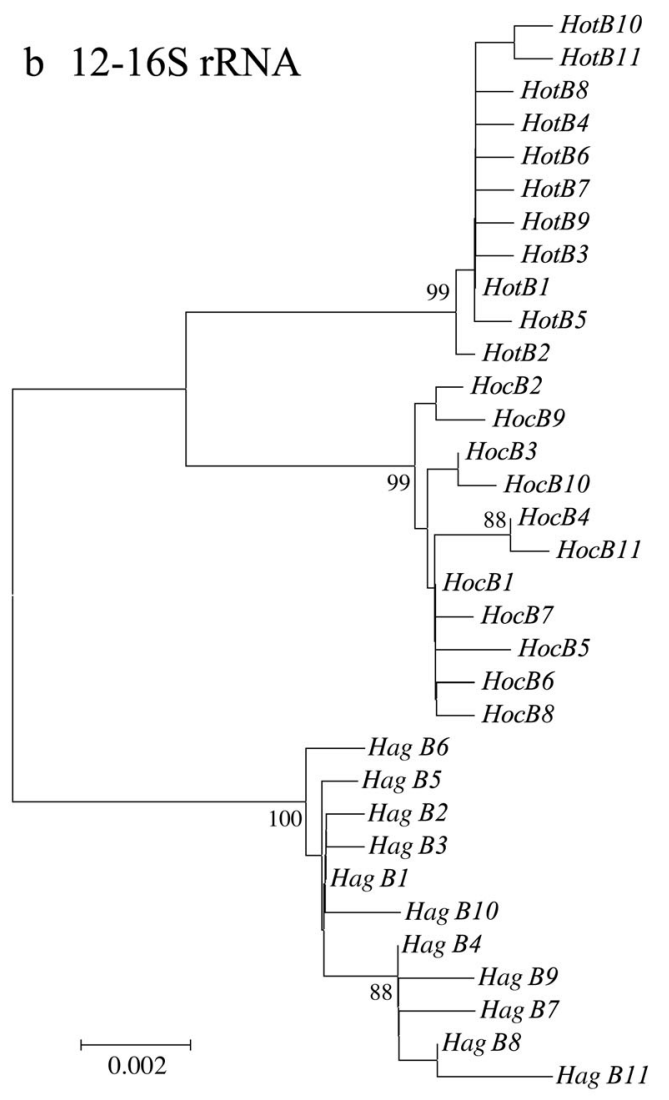

Fig. 3. Hexagrammos spp. Phylogenetic tree of (a) Cytb and (b) 12-16S rRNA haplotypes. Numbers on nodes indicate frequency with this node was recovered in a total of 1000 bootstrap replications 


\section{RESULTS}

\section{Nucleotide sequences of 3 species}

Nucleotide sequences were obtained for 986 base pairs (bp) of the Cytb region and $1421 \mathrm{bp}$ of the 12-16S rRNA region. A total of 40 and 33 haplotypes were detected in the Cytb and 12-16S regions, respectively, and sequences of variable nucleotide sites of these haplotypes are shown in Appendix 1 (Cytb) and Appendix 2 (12-16S rRNA), both available as Supplementary Material at www.int-res.com/articles/ suppl/b001p187_app.pdf. Haplotypes from both regions fell into 3 distinct clusters in neighbor-joined phylogenetic tree (Fig. 3), corresponding to morphological identifications (Appendix 3, available as Supplementary Material at www.int-res.com/articles/ suppl/b001p187_app.pdf). Cytb haplotypes Hot A1-13, Hag A1-12 and Hoc A1-15 were considered to be species-specific for Hexagrammos otakii, H. agrammus and $H$. octogrammus, respectively. Haplotypes for the 12-16S rRNA region, Hot B1-11, Hag B1-11 and Hoc B1-11, were specific for $H$. otakii, $H$. agrammus and $H$. octogrammus, respectively.

\section{APLP band patterns of the Cytb and the 12-16S rRNA regions}

PCR amplicons of the Cyt $b$ fragment in the multiplex APLP assay were expected to be $284 \mathrm{bp}$ (Hexagrammos otakii), $910 \mathrm{bp}$ (H. agrammus) and $631 \mathrm{bp}$ (H. octogrammus) in length and electrophoresis of these products confirmed diagnostic fragment patterns for the 3 species (Fig. 4a,b). In the 12-16S rRNA region, fragments of 927 bp (H. otakii), 446 bp (H. agrammus) and $1177 \mathrm{bp}$ (H. octogrammus) in length (Fig. $4 \mathrm{c}, \mathrm{d}$ ) were produced by APLP. All the results from the APLP analysis corresponded with haplotype identifications and unexpected banding patterns were not observed in either the Cytb or the 12-16S fragments. APLP analysis for 32 larval specimens produced a band pattern specific to each species (Fig. 4b,d). In several cases, band patterns from larvae differed from the observed species of territorial male guarding the egg mass (Fig. 4b,d): 2 and 5 larvae from egg masses guarded by $H$. otakii and $H$. agrammus males were identified as having $H$. octogrammus mothers, respectively; and one larva from an egg mass guarded by a $H$. octogrammus male was identifies as having a $H$. agrammus mother (Appendix 3 ).

M 123456789101112131415161718192021222324 M 123456789101112131415161718192021222324
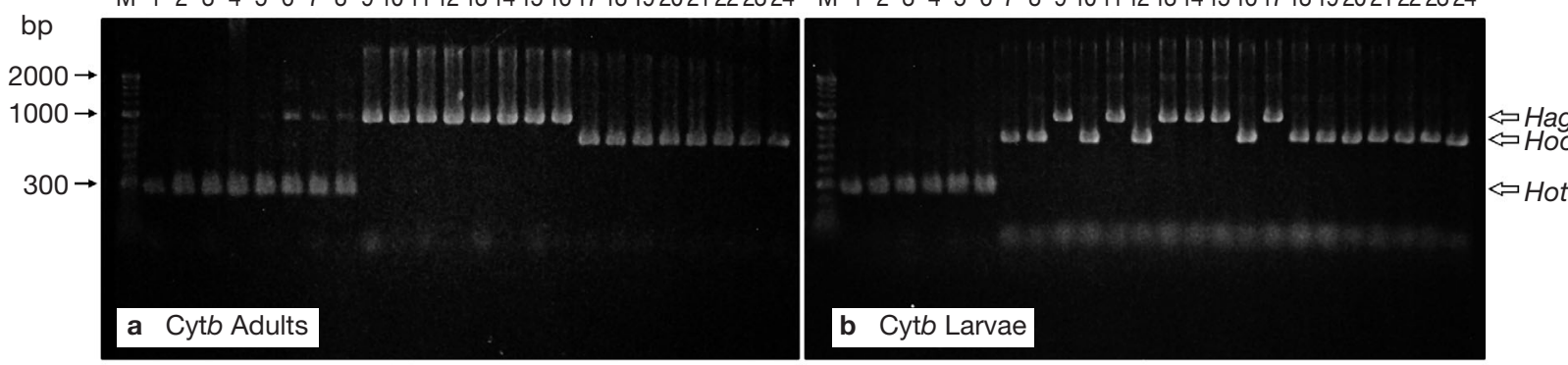

$\mathrm{bp}$

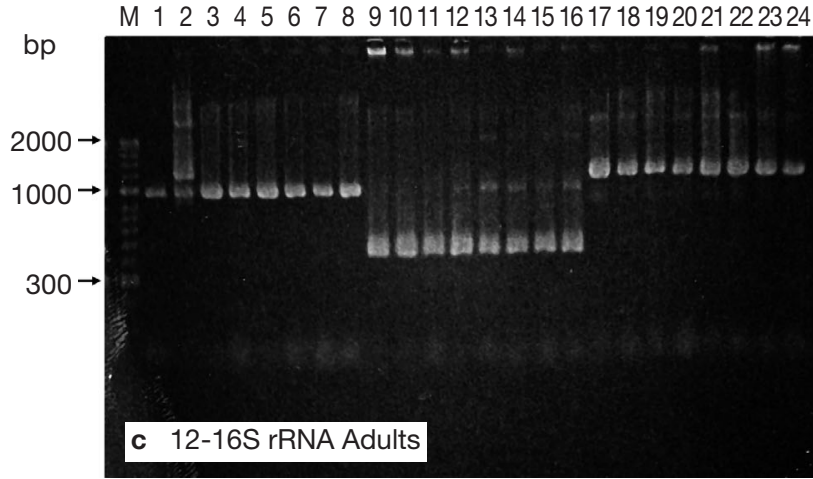

M 123456789101112131415161718192021222324

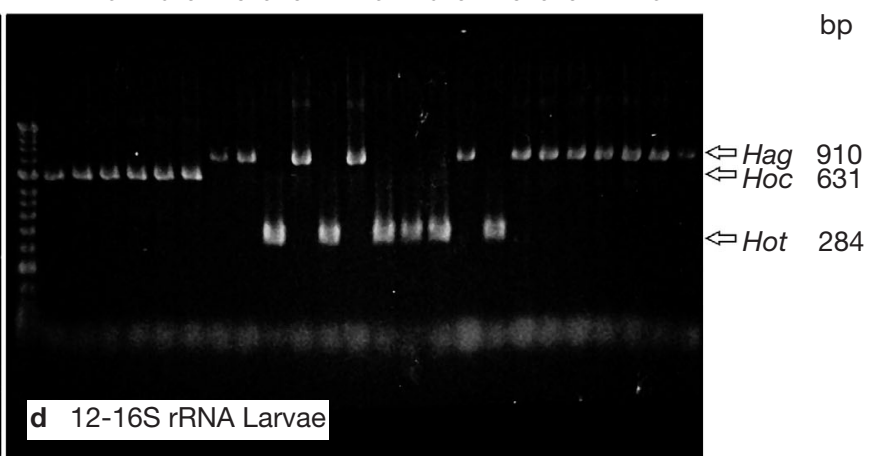

Fig. 4. Hexagrammos spp. Electrophoretic patterns of amplified product length polymorphism (APLP) from the (a,b) mitochondrial Cytb and (c,d) 12-16S rRNA regions of 3 Hexagrammos species. Adult specimens: Lanes 1 to 4, H. otakii from Usujiri; Lanes 5 to 8, H. otakii from Mie; Lanes 9 to $12, H$. agrammus from Usujiri; Lanes 13 to 16, H. agrammus from Mie; Lanes 17 to 20 , $H$. octogrammus from Usujiri; and Lanes 21 to 24, H. octogrammus from Akkeshi. Larval specimens hatched from egg masses collected in the male territories of 3 Hexagrammos species: Lanes 1 to 8, egg masses in the territories of $H$. otakii; Lanes 9 to 16 , those in $H$. agrammus territories; Lanes 17 to 24, those in H. octogrammus territories. Lane M contains molecular size standards. Open arrows labeled Hot, Hag and Hoc show the species-specific fragments of H. otakii, $H$. agrammus and H. octogrammus, respectively 
Table 3. Hexagrammos spp. Size (bp) of restriction enzyme digestion fragments from the Cyt $b$ and 12-16S rRNA regions for PCR-RFLP identification of 3 Hexagrammos spp. Species abbreviations are given in Table 2

\begin{tabular}{|c|c|c|c|c|c|c|c|c|c|c|c|c|}
\hline \multirow{3}{*}{$\begin{array}{l}\text { Locus: } \\
\text { Enzyme: } \\
\text { Species: }\end{array}$} & \multirow{2}{*}{\multicolumn{6}{|c|}{ - Cyt $b$}} & \multirow{2}{*}{\multicolumn{4}{|c|}{ - 12-16S rRNA }} & \multirow{2}{*}{\multicolumn{2}{|c|}{$M s p$ I }} \\
\hline & & & & & Rsa I & & & & & & & \\
\hline & Hot & Hag & HoC & Hot & Hag & Hoc & Hot & Hag & Hoc & Hot & Hag & Hoc \\
\hline & 480 & 489 & 1134 & 900 & 592 & 508 & 379 & 387 & 387 & 821 & 982 & 821 \\
\hline & 303 & 480 & & 234 & 308 & 392 & 345 & 379 & 379 & 439 & 439 & 439 \\
\hline & 228 & 123 & & & 234 & 234 & 278 & 278 & 278 & 161 & & 161 \\
\hline & 123 & 30 & & & & & 152 & 152 & 152 & & & \\
\hline & & 12 & & & & & 93 & 93 & 93 & & & \\
\hline & & & & & & & 88 & 88 & 88 & & & \\
\hline & & & & & & & 42 & 27 & 27 & & & \\
\hline & & & & & & & 27 & 17 & 17 & & & \\
\hline & & & & & & & 17 & & & & & \\
\hline
\end{tabular}

\section{RFLP restriction profiles}

Electrophoresis of PCR Cytb products digested by Hinf I and Rsa I were expected to show diagnostic fragment patterns for the 3 species (Table 3). When the PCR Cyt $b$ products were digested by Hinf I, 6 RFLP patterns were observed; Patterns A, D and F were the common patterns for Hexagrammos otakii, $H$. agrammus and $H$. octogrammus, respectively (Fig. 5a). Most RFLP results correctly reflected identification by phylogenetic analysis of haplotypes. However, several specimens produced exceptional band patterns; haplotypes of Hot A1, Hot A4, Hot A5, and Hot A13 (Appendix 1) gained a restriction site and exhibited Pattern $B$ (Fig. 5a). Two haplotypes (Hot A10 and Hot A11, Appendix 1) lost a restriction site, exhibiting Pattern C, and haplotype Hag A7 gained a restriction site, resulting in Pattern E (Fig. 5a). PCR Cyt $b$ products digested by Rsa I displayed 3 RFLP patterns; A, B and C were the common patterns to $H$. otakii, $H$. agrammus and $H$. octogrammus, respectively (Fig. 5b). Two haplotypes in H. octogrammus (Hoc A3 and Hoc A14, Appendix 1)

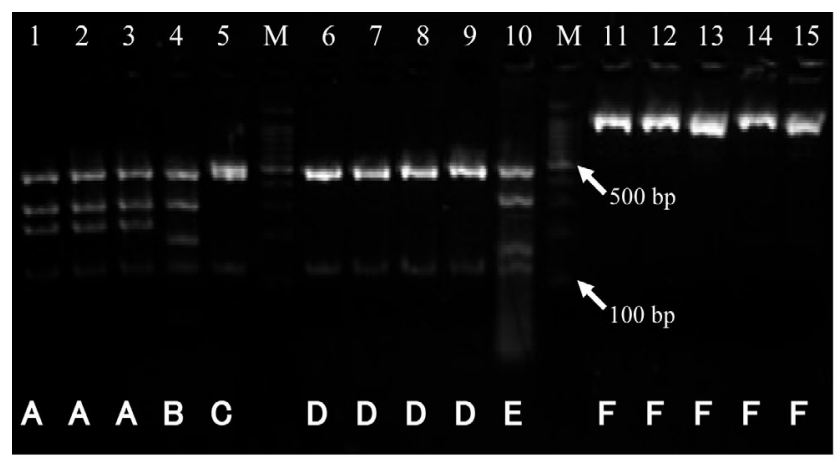

a Cytb Hinfl

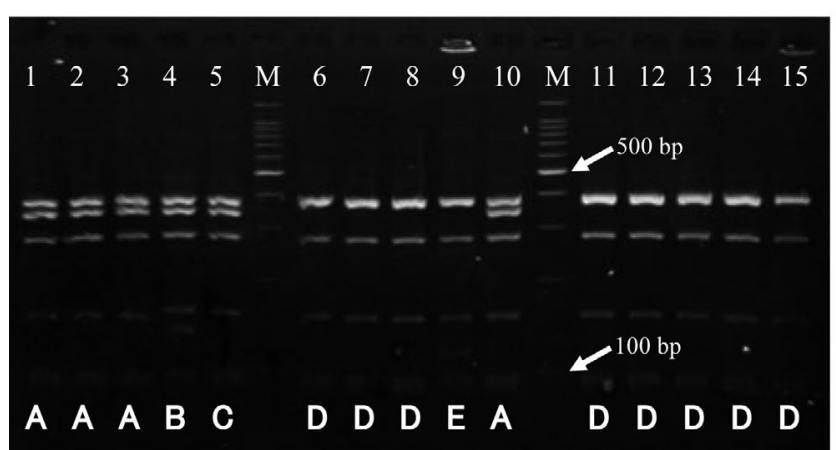

c $12-16 \mathrm{~S}$ rRNA Ddel

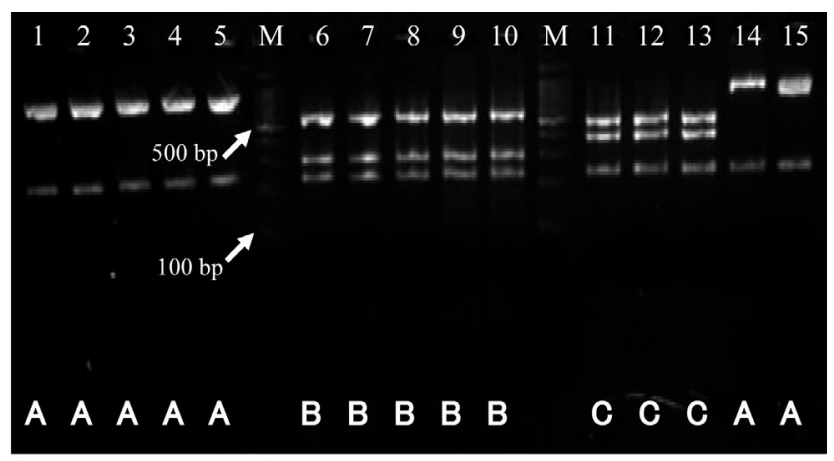

b Cytb Rsal

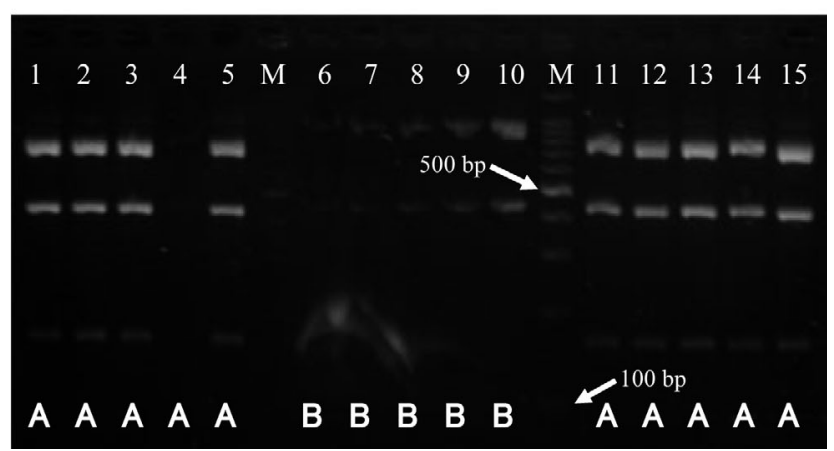

d 12-16S rRNA Mspl

Fig. 5. Hexagrammos spp. Electrophoretic patterns of restriction enzyme fragment products in adult specimens from (a,b) Cyt $b$ and (c,d) 12-16S rRNA regions digested with Hinf I (a), Rsa I (b), Dde I (c) and Msp I (d). Lanes 1 to 5, H. otakii; Lanes 6 to 10, H. agrammus; Lanes 11 to 15, H. octogrammus. Lane M contains molecular size standards. Alphabetic nomenclature at the bottom of each lane indicates each restriction pattern 
lost a restriction site, resulting in Pattern A (Fig. 5b) and leading to misidentification of $H$. octogrammus as H. otakii.

RFLP profiles of the 12-16S rRNA PCR products restricted by Dde I and Msp I did not discriminate among the 3 species by use of either enzyme alone. Fragment patterns produced by Dde I digestion were identical for only Hexagrammos otakii but did not distinguish between $H$. agrammus and $H$. octogrammus; and those produced by Msp I digestion were the same for $H$. otakii and $H$. octogrammus (Table 3). Again, most RFLP results correctly reflected the phylogenetic placement of haplotypes, with several specimens producing atypical band patterns. Five RFLP patterns were observed when the 12-16S rRNA PCR products were digested by Dde I; Pattern A was the pattern common to $H$. otakii and Pattern D was shared by both $H$. agrammus and H. octogrammus (Fig. 5c). However, 2 haplotypes in $H$. otakii (Hot B10 and Hot B11, Appendix 1) lost 2 and 1 restriction sites, respectively, producing Patterns B and C (Fig. 5c). One H. agrammus haplotype (Hag B9) lost a restriction site, resulting in the unique Pattern $\mathrm{E}_{\text {; }}$ and another (Hag B6) gained a restriction site resulting in the Pattern A common to $H$. otakii. When 12-16S PCR products were restricted by Msp I, 2 RFLP patterns were observed; Pattern A was shared by $H$. otakii and $H$. octogrammus and Pattern B was diagnostic for $H$. agrammus (Fig. 5d). All RFLP profiles from Msp I agreed with identifications based upon haplotype sequences.

\section{DISCUSSION}

The novel multiplex APLP method presented in this study achieved accurate identification of 3 Hexagrammos spp. using either the Cyt $b$ or 12-16S rRNA regions. APLP analysis provided unequivocal maternal identification of larvae hatched from egg masses guarded by territorial males (the presumed sire) and, in some cases, strongly inferred interspecific hybridization within this genus.

Important considerations for developing genetic assays applicable to studying hybrid zones of marine species are accuracy, speed and cost. Based upon these criteria, APLP appears to have substantial advantages over more conventional approaches, such as DNA sequencing and PCR-RFLP methods. Direct sequencing and phylogenetic identification should be the most reliable and informative method but requires more time (2 rounds of PCR) and expense than methods employing only a single PCR reaction. Although PCRRFLP analysis is faster and less expensive, it requires the cost of enzymes plus the time for restriction digests. In addition, some identification errors due to mutations at restriction sites were evident in this study based upon RFLP patterns for both the Cytb and 12-16S rRNA regions. In particular, the Cyt $b$ region contained 9 haplotypes for the 3 species which showed variant RFLP patterns. This region is moderately variable in these Hexagrammos spp. (151 substitutions in 145 polymorphic sites within $986 \mathrm{bp}$, Appendix 1), resulting in the loss or gain of restriction sites in some haplotypes and potential misidentification due to intraspecific variation. On the other hand, the $12-16 \mathrm{~S}$ region evolves most slowly in mtDNA (Mindel \& Honeycutt 1990) and the numbers of diagnostic sites in this region are limited (25 sites within $1421 \mathrm{bp}$, Appendix 2), exhibit less variation (62 substitutions in 60 polymorphic sites within $1421 \mathrm{bp}$, Appendix 2), and do not provide unequivocal diagnostic patterns for 3 Hexagrammos spp. based upon a single restriction enzyme.

The multiplex APLP analysis thus represents improvements upon accuracy and efficiency compared to PCR-RFLP. Properly designed species-specific primers used in the APLP method correctly assigned all specimens into the 3 Hexagrammos species inferring that APLP is robust to the effects of intraspecific variation. Moreover, the concurrent use of 4 primers ( 3 speciesspecific forward primers and a single reverse primer) in single reaction tube simplifies the procedure. Indeed, only one process of PCR was required to identify 3 Hexagrammos species using either the Cytb or the 12-16S rRNA regions.

To achieve accurate and rapid identification with APLP analysis, the following 5 points about designing species-specific primers and PCR conditions for the multiplex assay should be considered. (1) Each species-specific primer should be designed at sites that are fixed in one species and that differ from the other species, reducing the potential for misidentification caused by intraspecific variation. (2) All primers should have similar melting temperatures to amplify each PCR product consistently. When the melting temperatures of primers differ substantially, primers which have low melting temperatures fail to anneal at higher annealing temperatures, and primers with higher melting temperatures lose primer specificity at low annealing temperature. Therefore primer length and GC content should be adjusted to make them comparable in melting temperature. (3) Melting temperatures of all primers and the annealing temperature for PCR should be set comparatively high to achieve optimal primer specificity to the target sequences and to avoid primerto-primer annealing (Pank et al. 2001). In this study, the sequences of 2 primers, Cytb-Hag and 12-16S-Hot, differed from each other by only one base over a $20 \mathrm{bp}$ annealing site (Table 2). Despite such small differences in specificity, those primers strictly amplified each species-specific amplicon under high-stringency PCR 
conditions (annealing at $60^{\circ} \mathrm{C}$ ). (4) The $3^{\prime}$-end of each primer should not have complementary sequence with other primers in order to avoid primer-to-primer annealing, a condition of primer design used in this study (Table 2). (5) The annealing sites of species-specific primers should be located sufficiently far apart to amplify unambiguously diagnostic fragments between species in order to increase the speed of gel interpretation (Pank et al. 2001). In this study, diagnostic APLP fragments for the 3 Hexagrammos spp. were clearly discriminated by visual observation of the gel after 20 min of electrophoresis.

Overall, the multiplex APLP protocol represents an efficient, reliable, easy, rapid, and economical method for maternal identification of 3 Hexagrammos spp. and should accelerate studies of hybridization in other marine species.

Acknowledgements. We are grateful to Drs. Michael F. Canino and Satoshi Awata for comments on the manuscript. We also thank staff of the Fisheries Research Laboratory of Mie University and Akkeshi Marine Station of Hokkaido University for assistance in sample collection. This work was supported by a grant in aid for scientific research from the Ministry of Education, Science and Culture of Japan and grants from the Fisheries Agency of the Japanese government.

\section{LITERATURE CITED}

Arnold ML (1997) Natural hybridization and evolution. Oxford University Press, New York

Avise JC, Lansman RA (1983) Polymorphism of mitochondrial DNA in populations of higher animals. In: Nei M, Kohen RK (eds) Evolution of genes and proteins. Sinauer, Sunderland, MA p 147-164

Balanov AA, Antonenko DV (1999) First finding of Hexagramos agrammus $\times H$. octogrammus hybrids and new data about occurrence of $H$. agrammus (Hexagrammidae) in Peter the Great Bay (The Sea of Japan). J Ichthyol 39:149-156

Brykov VA, Podlesnykh AV (2001) Comparison of mitochondrial DNA in 2 greenling species and their hybrids (CEM. Hexagrammidae: Pisces) from Peter the Great Bay (Sea of Japan). Russ J Genet 37:1400-1402

Crow KD, Powers DA, Bernardi G (1997) Evidence for multiple maternal contributors in nests of kelp greenling (Hexagrammos decagrammus, Hexagrammidae). Copeia 1997:9-15

Dendis M, Horvath R, Michalek J, Ruzicka F, Grijalva M, Bartos M, Benedik J (2003) PCR-RFLP detection and species identification of fungal pathogens in patients with febrile neutropenia. Clin Microbiol Infect 9:1191-1202

Excoffier L, Laval G, Schneider S (2005) Arlequin v. 3.0: an integrated software package for population genetics data analysis. Evol Bioinform Online 1:47-50

Felsenstein J (1985) Confidence-limits on phylogenies: an approach using the bootstrap. Evolution 39:783-791

Editorial responsibility: Matthias Seaman (Assistant Editorin-Chief), Oldendorf/Luhe, Germany
Hosseini R, Keller MA, Schmidt O, Framenau VW (2007) Molecular identification of wolf spiders (Araneae: Lycosidae) by multiplex polymerase chain reaction. Biol Control 40:128-135

Jiggins CD, Mallet J (2000) Bimodal hybrid zones and speciation. Trends Ecol Evol 15:250-255

Kimura M (1980) A simple method for estimating evolutionary rates of base substitutions through comparative studies of nucleotide sequences. J Mol Evol 16:111-120

Kumar S, Tamura K, Nei M (2004) MEGA3: Integrated software for molecular evolutionary genetics analysis and sequence alignment. Brief Bioinform 5:150-163

Mindell DP, Honeycutt RL (1990) Ribosomal RNA in vertebrates: evolution and phylogenetic applications. Annu Rev Ecol Syst 21:541-566

Nakabo T (2000) Fishes of Japan with pictorial keys to the species. Tokai University Press, Tokyo (in Japanese)

Nei M (1987) Molecular evolutionary genetics. Columbia University Press, New York

Nielsen EE, Nielsen PH, Meldrup D, Hansen MM (2004) Genetic population structure of turbot (Scophthalmus maximus L.) supports the presence of multiple hybrid zones for marine fishes in the transition zone between the Baltic Sea and the North Sea. Mol Ecol 13:585-595

Pank M, Stanhope M, Natanson L, Kohler N, Shivji M (2001) Rapid and simultaneous identification of body parts from the morphologically similar sharks Carcharhinus obscurus and Carcharhinus plumbeus (Carcharhinidae) using multiplex PCR. Mar Biotechnol 3:231-240

Rutenberg EP (1970) Survey of the fishes of Family Hexagrammidae. In: Rass TS (ed) Greenlings: taxonomy, biology and interoceanic transplantation. Israel Program for Scientific Translations, Moskva, p 1-103

Saitou N, Nei M (1987) The neighbor-joining method: a new method for reconstructing phylogenetic trees. Mol Biol Evol 4:406-425

Scribner KT, Page KS, Bartron ML (2000) Hybridization in freshwater fishes: a review of case studies and cytonuclear methods of biological inference. Rev Fish Biol Fish 10:293-323

Shinohara G (1994) Comparative morphology and phylogeny of the Suborder Hexagrammoidei and related taxa (Pisces: Scorpaeniformes). Mem Fac Fish Hokkaido Univ 41:1-97

Umetsu K, Tanaka M, Yuasa I, Adachi N and others (2005) Multiplex amplified product-length polymorphism analysis of 36 mitochondrial single-nucleotide polymorphisms for haplogrouping of East Asian populations. Electrophoresis 26:91-98

van Herwerden L, Doherty PJ (2006) Contrasting genetic structures across 2 hybrid zones of a tropical reef fish, Acanthochromis polyacanthus (Bleeker 1855). J Evol Biol 19:239-252

Yabe M, Matsuura K, Arai R (1991) The fishes of the northern part of Hokkaido. Memoirs of the National Science Museum 24:117-130 (in Japanese)

Yanagimoto T (2003) Identification of 7 greenling species using polymerase chain reaction-restriction fragment length polymorphism (PCR-RFLP) analysis of mitochondrial DNA. Nippon Suisan Gakkai Shi 69:726-732 (in Japanese with English abstract)

Yanagimoto T, Kobayashi T (2004) Molecular phylogeny of 7 greenlings by the mitochondrial DNA analysis. DNA polymorphism 12:87-89 (in Japanese)

Submitted: June 1, 2007; Accepted: November 29, 2007

Proofs received from author(s): December 25, 2007 